\title{
Exosome: A Novel Nanocarrier Delivering Noncoding RNA for Bone Tissue Engineering
}

\author{
Keda Liu $\mathbb{D},{ }^{1}$ Nanjue Cao $\mathbb{D}^{2},{ }^{2}$ Yuhe Zhu $\mathbb{D}^{1},{ }^{1}$ and Wei Wang $\mathbb{D}^{1}$ \\ ${ }^{1}$ School and Hospital of Stomatology, China Medical University, Liaoning Provincial Key Laboratory of Oral Diseases, \\ Shenyang 110001, China \\ ${ }^{2}$ The Fourth Affiliated Hospital, Zhejiang University School of Medicine, Yiwu 322000, China
}

Correspondence should be addressed to Wei Wang; wwang75@cmu.edu.cn

Received 9 July 2020; Accepted 31 July 2020; Published 14 August 2020

Academic Editor: Hui-Qi Xie

Copyright $\odot 2020$ Keda Liu et al. This is an open access article distributed under the Creative Commons Attribution License, which permits unrestricted use, distribution, and reproduction in any medium, provided the original work is properly cited.

Bone growth and metabolism are mainly regulated by a series of intracellular molecules and extracellular stimuli. Exosome, as a nanoscale substance secreted to the outside of the cells, plays an extensive role in intercellular communication. This review provides theoretical references and evidences for further exploration of exosomes as noncoding RNA carriers to regulate bone tissue recovery through the following aspects: (1) basic characteristics of exosomes, (2) research progress of exosomal noncoding RNA in bone tissue engineering, (3) current status and advantages of engineering exosomes as nanocarriers for noncoding RNA delivery, and (4) problems and application prospects of exosome therapy in the field of orthopedics.

\section{Introduction}

Destructive osteopathy is mainly due to the failure of the bone remodeling process, including enhanced osteoclast activity or reduced osteoblast generation $[1,2]$. Osteoarthritis, osteoporosis, etc. will lead to a continuous decline in the quality of patients' life $[3,4]$, deemed to be an important global health problem $[5,6]$. The process of bone remodeling is to repair bone damage and restore aging bone tissue [7]. This is the prerequisite for maintaining mass and mechanical strength of bone [8]. Mutual regulation of osteoblasts and osteoclasts is essential for bone remodeling [9], dominated by molecular signals $[10,11]$.

Extracellular vesicles are natural nanoscale particles secreted by cells. They are spherical bilayer membrane vesicles with diameters ranging from $30 \mathrm{~nm}$ to $1000 \mathrm{~nm}$, including exosomes of uniform size (30-150 nm), microvesicles of varying sizes $(50-1000 \mathrm{~nm})$, and apoptotic bodies [12]. Recent studies reported that the key factor for bone reconstruction was exosome [13]. These organelles play a crucial role in intercellular messengers, transferring bioactive molecules to nearby or distant cells under physiological and pathological conditions $[14,15]$. Noncoding RNAs in exosomes supply a method that cells can straightly regulate the expression of pro- tein in target cells. As a kind of nanomaterial, exosome has been explored in the field of diagnostic [16], therapeutics [17], and drug delivery [18] (Figure 1).

Existing drug carriers, such as artificially manufactured liposomes, can cause accumulated toxicity and immunogenicity in the body, thus limiting the wide application of such drug carriers [20,21]. As a natural drug delivery carrier, exosomes have significant advantages of biocompatibility, high stability, and targeting. In order to better understand the mechanism of exosomes as noncoding RNA vectors regulating bone remodeling, we reviewed the newest findings on the feature and role of exosomes in bone formation. In addition, we focused on elaborating the feasible clinical application of bone exosomes and the characteristics of exosomal noncoding RNAs in the regulation of bone reconstruction.

\section{Biological Characteristics of Exosomes}

Exosome was first discovered in 1981, considered cellular trash initially [22]. Subsequently, exosomes caught the interest of immunologists in the 1990s. Raposo et al. in 1996 reported that exosomes have the ability of antigen presentation, activating $\mathrm{T}$ cell immune response [23]. In addition, 


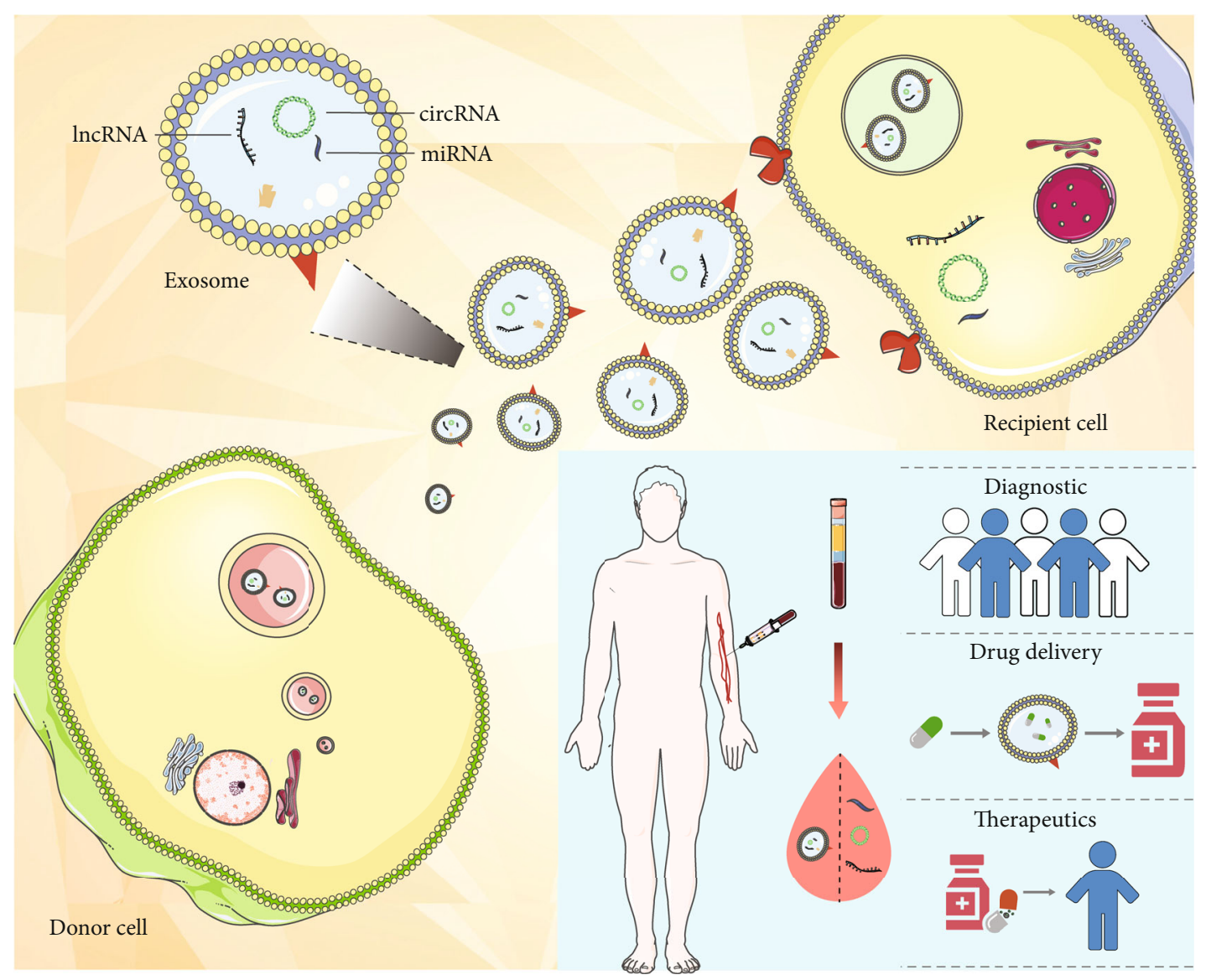

FIgURE 1: Exosome production, secretion, and cargo transfer from donor cells to recipient cells. The inset shows the clinical application of noncoding RNA exosomes [19].

exosomes were found to carry miRNAs and mRNAs for intercellular communication in 2007. Most importantly, the mechanism of exosomal transport was cracked by three independent groups [24-26]. The history, biomarkers, and functions of exosomes are shown in Figure 2.

Exosomes are membrane vesicles with diameters between 30 and $150 \mathrm{~nm}[27,28]$ (Figure 3). They are derived from body cells including tumor cells [29, 30]. Studies revealed that exosomes are also secreted from bone-related cells (osteoclasts, osteoclast precursors, osteoblasts, and MSCs) [31-33]. Exosomes reflect the complex molecular processing that occurs inside the parent cells and are more appropriate as a potential replacement for parent cell in body fluids. Multiple studies have confirmed the loyalty of exosomal cargo to parental cells $[34,35]$. Exosomes can encapsulate fragments of genomic and different kinds of RNA, such as miRNA, IncRNA, circRNA, and ribosomal RNA [36-39].

\section{Exosomes from Osteoclasts and Osteoblasts}

3.1. Osteoclast Exosomes. Exosomes secreted by osteoclasts may provide clues on how to coordinate bone absorption and construction. In calcitriol-stimulated mouse bone marrow (C-SMM), osteoclasts and osteoblasts differentiated synergistically within six days. Osteoclast precursor-derived exosomes stimulated the proliferation of osteoclasts in CSMM, while exosomes of mature osteoclasts inhibited osteoclast formation $[13,40]$. Osteoclast exosomes stimulate the osteoblasts and other nonosteoclasts in a paracrine manner and produce factors that regulate osteoclast differentiation.

miRNA-214, involved in bone remodeling, adjusts Osterix and activates transcription factor (ATF) 4, which is an essential transcription factor in osteogenesis process [41, 42]. Higher levels of miRNA-214 were noted in the plasma of fractured elderly women and ovariectomized mouse. In vitro, by using transwell membranes (that only permitted exosomes through), exosomal miRNA-214 was transmitted from osteoclasts to osteoblasts, inhibiting proliferation and mineralizing activity of osteoblast in vitro and vivo [43,44].

3.2. Osteoblast Exosomes. Osteoblasts release exosomes containing receptor activator RANKL. These exosomes induce osteoclast precursors to differentiate to osteoclasts [31]. Osteoblasts release RANKL exosomes and osteoclasts release RANK exosomes. Studies have shown that the RANKLRANK-osteoprotectin signal network is the essence of bone biology. RANKL exosome from osteoblasts may be capable of promoting osteoclast formation and activity without direct intercellular contact. RANK exosome may inhibit RANKL in a method the same as osteoprotectin. Both RANKL and 
(a)

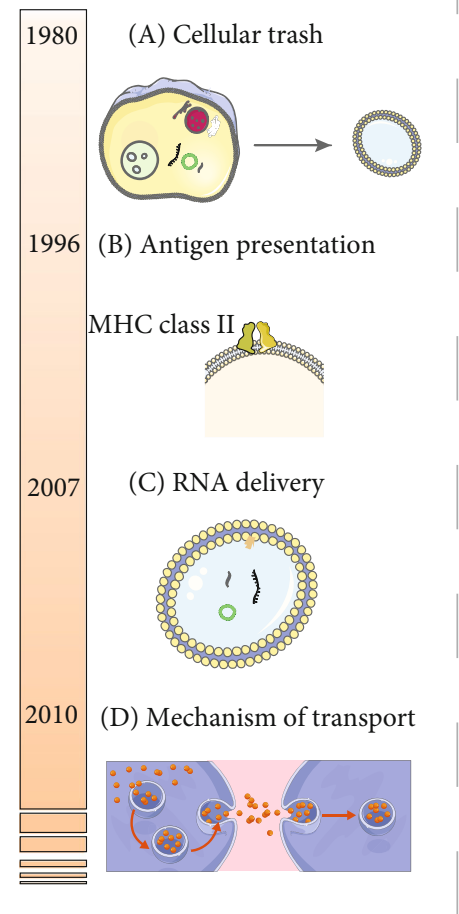

(b)
Cell differentiation

Tumor invasion

Angiogenesis

Metabolic reprogramming

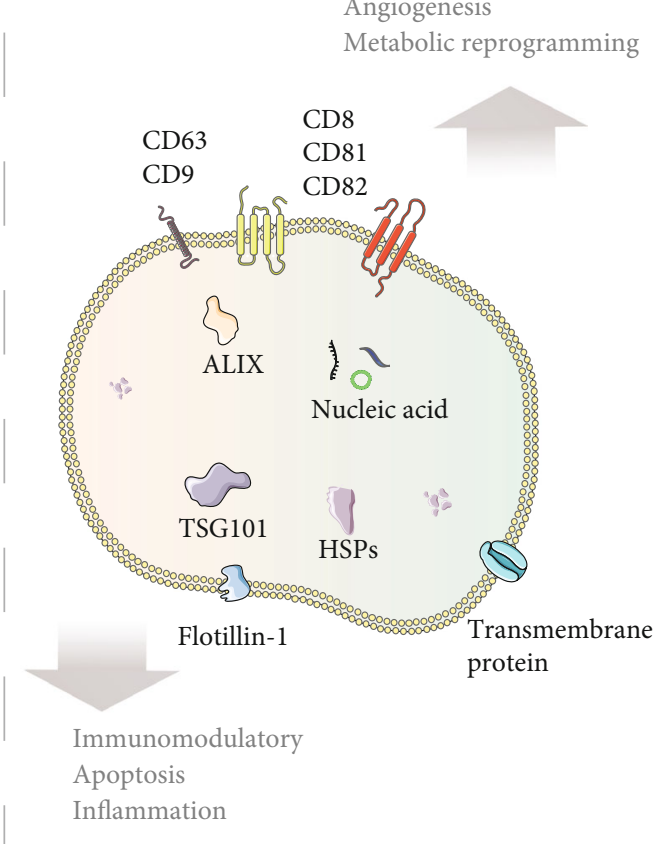

Figure 2: (a) Historical key developments in exosome research. (b) Biomarkers and functions of exosome.

RANK-containing exosome may be able to fuse in their target cells to release regulatory molecules, which could assist to reprogram target cells [45].

\section{The Roles of Exosomal Noncoding RNAs in Bone Growth}

Noncoding RNA refers to RNA that does not encode protein. They have biological functions at the RNA level. Noncoding RNAs are generally divided into 3 categories according to their size: less than $50 \mathrm{nt}$, including microRNA (miRNA), small interfering RNA (siRNA), and piwi-interacting RNA (piRNA); $50 \mathrm{nt}$ to $500 \mathrm{nt}$, including nuclear small RNA (snRNA) and small nucleolar RNA (snoRNA); and greater than $500 \mathrm{nt}$, long noncoding RNA (lncRNA) and circular RNA (circRNA) [46, 47]. This article reviews current research hotspots of osteoarthritis: miRNA, lncRNA, and circRNA.

4.1. miRNA. The latest two years of exosome miRNA in the regulation of bone growth and development is listed in Table 1. Exosome miR-128-3p regulates osteogenesis and fracture healing by targeting Smad5 [48]. Decreasing miR221-3p in exosomes can significantly reduce chondrocyte proliferation and migration in vitro [49]. Exosome miR-17 secreted by keratinocytes can induce osteoclast differentiation [30]. By freeze and thaw method, researchers combined exosomes and miR-140 to promote cartilage differentiation of bone marrow stem cells, thereby enhancing cartilage repair and regeneration [50]. Human umbilical cord mesenchymal stem cell exosomes can effectively inhibit bone marrow mesenchymal stem cell apoptosis and prevent osteoporosis in rats.
The mechanism is mediated by the miR-1263/Mob1/Hippo signaling pathway [51]. Exosome miR-8485 promotes cartilage differentiation of bone marrow mesenchymal stem cells by regulating the $\mathrm{Wnt} / \beta$-catenin pathway [52].

Studies on miRNAs have demonstrated that the regulation of the target genes affects the expression of regulators upstream and downstream of each signaling pathway, to regulate the osteogenic differentiation process [54]. Runx2 is a transcription factor that plays an important role in osteoblast differentiation [55], which is precisely or indirectly regulated by many miRNAs, including miR-221 [56, 57], miR-133a-5p [58], miR-467g [59], miR-218 [60, 61], and miR-210 [62]. The expression of Osx can be downregulated by some miRNAs, inhibiting osteogenic differentiation, such as miR-145 [63] and miR-143 [64, 65]. Some miRNAs that regulate the expression of bone-related gene have not been studied in exosomes, providing clues to the research of exosomes in the field of orthopedics (Table 2).

4.2. $\ln c R N A$. The lncRNA-miRNA-mRNA regulation model plays a critical role in osteogenic differentiation [66]. IncRNA can serve as a competitive endogenous RNA, competing for miRNA binding sites to reduce its direct impact on mRNA. lncRNA MALAT1 can competitively bind to miR-30, inhibiting the interaction between miR-30 and Runx 2 to upregulate the transcription level of Runx2 and strengthen osteogenic differentiation of adipose mesenchymal stem cells [67]. Study revealed that IncRNA TUG1 [68], IncRNA PCAT1 [69], and lncRNA HIF1A-AS2 also indirectly regulate the activity of osteogenesis-related signaling molecules by adsorbing miRNA [70]. Downregulated lncRNA MEG3 


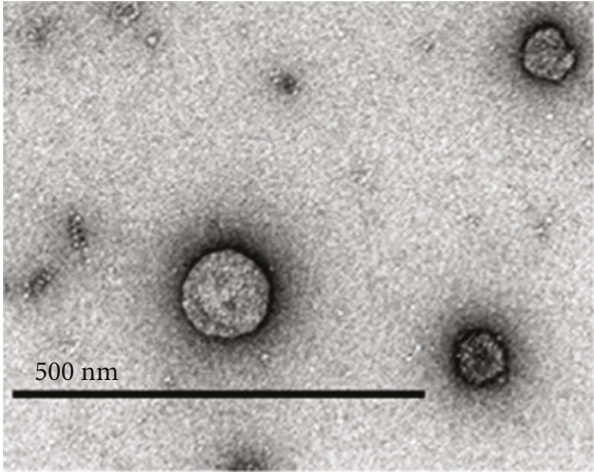

(a)

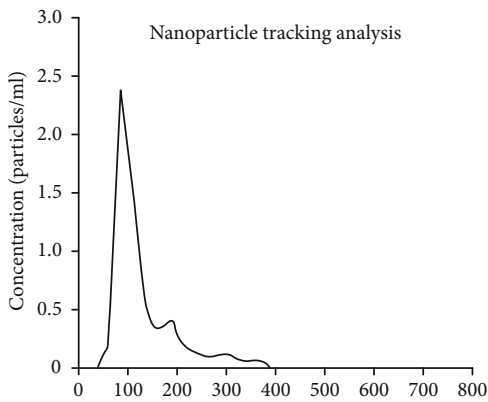

(c)

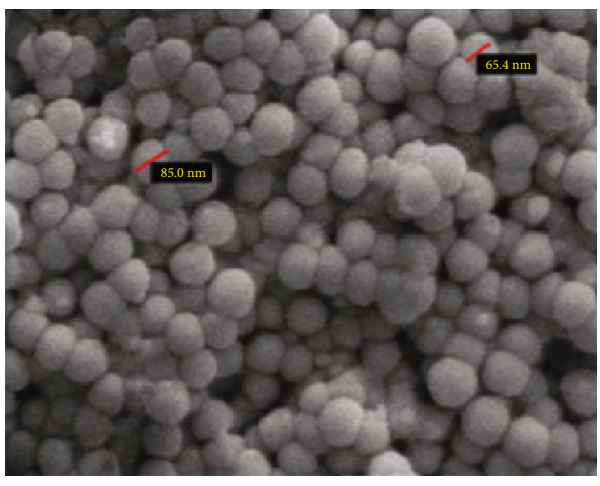

(b)

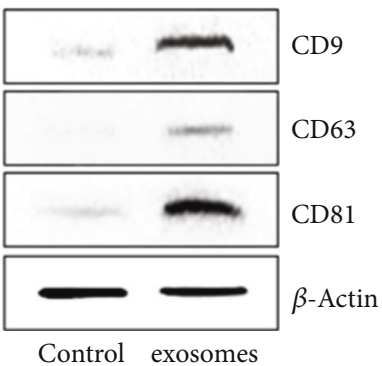

(d)
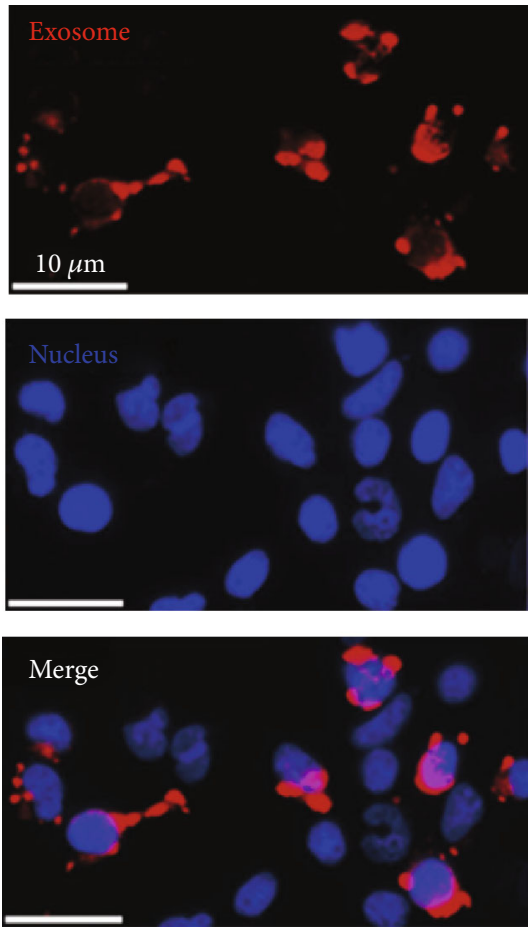

(e)

FIGURE 3: Characterization and cellular uptake of exosomes. As shown in (a) and (b), the morphology of exosomes was observed under TEM and SEM. In (c) and (d), exosome is a round membranous vesicle with a diameter of about 30-150 nm and the results of western blot showed that exosome was able to express marker proteins CD9, CD81, and CD63. In (e), to verify whether exosome interacts with cell, exosome labeled by Dil and receptor cell were cocultured in vitro for $6 \mathrm{~h}$. Under a fluorescence microscope, over $85 \%$ of cell showed positive result of Dil, indicating that the Dil-labeled exosome has been efficiently transferred to receptor cells [30, 35, 53]. (a-d) Copyright 2020 BBRC published by Elsevier Ltd. (b) Copyright 2019 EXCLI J published by University of Mainz. (c) Copyright 2020 Int Immunopharmacology published by Elsevier Ltd. 
TABLE 1: List of miRNA deliveries by exosome in both basic and clinical research of bone formation.

\begin{tabular}{|c|c|c|c|c|c|}
\hline miRNA & $\begin{array}{l}\text { Target } \\
\text { gene }\end{array}$ & Resource & $\begin{array}{l}\text { Recipient } \\
\text { cells }\end{array}$ & Mechanism and result & Ref. \\
\hline miR-128-3P & Smad5 & MSCs & MSCs & $\begin{array}{l}\text { miR-128-3p was highly expressed in aged exosome, inhibiting fracture healing } \\
\text { by targeting Smad5. }\end{array}$ & {$[48]$} \\
\hline miR-221-3p & & CPCs & $\begin{array}{l}\text { Murine } \\
\text { chondrocytes }\end{array}$ & $\begin{array}{l}\text { In vivo experiments confirmed that miR-221-3p was highly enriched in CPCs- } \\
\text { Exos, which can stimulate chondrocyte proliferation and migration. }\end{array}$ & [49] \\
\hline miR-140 & & $\begin{array}{l}\text { Freeze and } \\
\text { thaw method }\end{array}$ & BMSCs & $\begin{array}{l}\text { miR-140 was fused into exosomes by freezing and thawing, promoting the } \\
\text { differentiation of BMSCs into chondrocytes.[ }\end{array}$ & {$[50]$} \\
\hline $\operatorname{miR}-1263$ & Mob1 & HUC-MSCs & BMSCs & $\begin{array}{l}\text { Exosomes inhibit BMSC apoptosis through miR-1263/Mob1/Hippo signaling } \\
\text { pathway. }\end{array}$ & {$[51]$} \\
\hline miR-8485 & $\begin{array}{l}\text { DACT1, } \\
\text { GSK3B }\end{array}$ & Chondrocytes & BMSCs & $\begin{array}{l}\text { Exosomal miR-8485 regulated the Wnt/ } \beta \text {-catenin pathways to promote } \\
\text { chondrogenic differentiation of BMSCs. }\end{array}$ & {$[52$} \\
\hline miR-192-5p & RAC2 & BMSCs & & $\begin{array}{l}\text { The exosomal miR-192-5p of BMSCs can delay the inflammatory response of } \\
\text { rheumatoid arthritis by regulating the expression of proinflammatory factors. }\end{array}$ & {$[53$} \\
\hline miR-375 & IGFBP3 & hASCs & BMSCs & $\begin{array}{l}\text { Exosomes derived from hASCs overexpressing miR-375 promoted bone } \\
\text { regeneration by binding to IGFBP3. }\end{array}$ & {$[84]$} \\
\hline $\operatorname{miR}-26 a-5 p$ & PTGS2 & BMSC & $\begin{array}{l}\text { Synovial } \\
\text { fibroblasts }\end{array}$ & $\begin{array}{c}\text { The hBMSC-derived exosome- miR-26a-5p inhibited the damage of synovial } \\
\text { fibroblasts by targeting PTGS2. }\end{array}$ & {$[85$} \\
\hline miR-155 & & VECs & Macrophages & $\begin{array}{l}\text { VEC-Exos was rich in miR-155, which ind } \\
\text { by interacting with macrophages to impro }\end{array}$ & {$[86$} \\
\hline miR-129-5p & Sp1 & MMs & hMSCs & $\begin{array}{l}\text { Multiple myeloma (MM) exosome miR-129-5p reduced alkaline phosphatase } \\
\text { (ALPL) activity by inhibiting the expression of transcription factor Sp1 in } \\
\text { hMSCs. }\end{array}$ & {$[87]$} \\
\hline miR-17 & RANKL & Keratinocytes & Osteoclasts & $\begin{array}{c}\text { The exosomal miR-17 secreted by keratinocytes with middle ear } \\
\text { cholesteatoma can upregulate RANKL in fibroblasts and induce osteoclast } \\
\text { differentiation. }\end{array}$ & {$[30]$} \\
\hline
\end{tabular}

MSCs: mesenchymal stem cells; BMSCs: bone marrow mesenchymal stem cells; HUC-MSCs: human umbilical cord mesenchymal stem cells; hASCs: human adipose mesenchymal stem cells; VECs: vascular endothelial cells; CPCs: chondrogenic progenitor cells; MMs: multiple myelomas.

promotes osteogenic differentiation of human dental follicle stem cells by epigenetically regulating the Wnt pathway [71]. Researchers have indicated that exosome lncRNAMALAT secreted by bone marrow mesenchymal stem cells enhanced osteoblast activity in osteoporotic mice [72]. Exosomal lncRNA-RUNX2-AS1 secreted by multiple myeloma cells can reduce osteogenic differentiation of MSC [73].

4.3. $\operatorname{circRNA}$. Increasing evidence indicates the various functions of circRNA in bone marrow mesenchymal stem cell osteogenesis, which proves to be a valuable checkpoint for the treatment of bone diseases [74]. CircRNA_436 might be a part of the critical regulators of periodontal ligament stem cell differentiation by coordinating with $\mathrm{miR}-107$ and $\mathrm{miR}-$ 335 to affect the Wnt/ $\beta$-catenin pathway [75]. CircRNA_ 0127781 may serve as one of the essential regulators in the inhibition of osteoblast differentiation by interacting with miR-210 and miR-335 [76-78]. CircRNA_33287 would block miR-214-3p to intensify the osteogenesis process and active the construction of ectopic bone [79]. Both circRNA_19142 and circRNA_5846 target miR-7067-5p to regulate osteoblast differentiation [80]. Lipopolysaccharide (LPS) is indicated to promote bone resorption by activating TLRs [81]. GO analysis showed that circRNA_3140 is related to the TLR signaling pathway [75]. The mechanism of exosomal circRNA in the regulation of osteogenic differentiation is seldom studied. However, the circular structure of circRNA makes it more stable than linear RNA and difficult to be degraded [82]. It has great research potential in exosome engineering. Studies have shown that during the osteogenic differentiation of periodontal ligament stem cells, differentially expressed circRNAs are rich in membranebound vesicles [83]

\section{Engineering Exosomes as Nanocarrier for Noncoding RNA Delivery}

5.1. Methods of Exosome Extraction. The separation and purification of exosomes have always been a concern of researchers. It is crucial to obtain high-purity exosomes for subsequent research. Researchers currently use ultracentrifugation [91], immunomagnetic beads [92], ultrafiltration [93], size-exclusion chromatography [94], or kits to achieve exosomes (Figure 4). In Table 3, we summarize several methods for extracting exosomes and list their characteristics.

5.2. Merging Therapeutic RNA into Exosomes. Exosome cargo with therapeutic activity is not restricted to naturally occurring cell-derived biomolecules. Instead, exosomes can also carry exogenous therapeutic molecules. Exosomes have been engineered to bind therapeutic molecules, including protein [95], small molecule drugs [96], peptide ligands [97], and therapeutic RNA [98, 99]. Researchers have used multiple methods to engineer exosomes for cargo delivery, including incubation with saponin, electrical stimulation, sonication 
TABLE 2: List of miRNAs in bone formation.

\begin{tabular}{|c|c|c|c|c|}
\hline miRNA & $\begin{array}{l}\text { Target } \\
\text { genes }\end{array}$ & Cell type & Mechanism and result & Ref. \\
\hline $\operatorname{miR}-221$ & $\begin{array}{l}\text { ZFPM2, } \\
\text { Runx2 }\end{array}$ & Osteoblasts & $\begin{array}{l}\text { miR-221 inhibited osteoblast differentiation by targeting ZFPM2 } \\
\text { and Runx2 to reduce the expression levels of osteocalcin (OC), alkaline phosphatase } \\
\text { (ALP), and collagen, type I, } \alpha 1 \text { (COL1A1). }\end{array}$ & $\begin{array}{l}{[56,} \\
57]\end{array}$ \\
\hline $\operatorname{miR}-218$ & Runx2 & Osteoclasts & $\begin{array}{l}\text { miR-218 participated in the negative regulation of osteoclastogenesis and bone resorption } \\
\text { by inhibiting the p38MAPK-c-Fos-NFATc1 signaling pathway. }\end{array}$ & $\begin{array}{l}{[60,} \\
61]\end{array}$ \\
\hline $\operatorname{miR}-210$ & Runx2 & MSCs & $\begin{array}{l}\text { Overexpression of miR-210 in MSC led to the differentiation of MSC into osteoblasts by } \\
\text { upregulating Runx2, ALP, and osteocalcin. }\end{array}$ & {$[62]$} \\
\hline $\operatorname{miR}-145$ & $\begin{array}{l}\text { Smad3, } \\
\text { SEMA3A }\end{array}$ & BMSCs & $\begin{array}{l}\text { MicroRNA-145 suppressed osteogenic differentiation of hBMSCs partially via targeting } \\
\text { Smad3 and SEMA3A. }\end{array}$ & {$[63]$} \\
\hline $\operatorname{miR}-143-3 p$ & BMPR2 & BMSCs & $\begin{array}{c}\text { miR-143-3p regulated the early chondrogenic differentiation of BMSCs and promoted } \\
\text { cartilage damage repair by targeting BMPR } 2 .\end{array}$ & $\begin{array}{l}{[64,} \\
65]\end{array}$ \\
\hline $\operatorname{miR}-542-3 p$ & SFRP1 & Osteoblasts & miR-542-3p prevented ovariectomy-induced osteoporosis in rats by targeting SFRP1. & {$[88]$} \\
\hline $\operatorname{miR}-433-3 p$ & DDK1 & Osteoblasts & MicroRNA-433-3p promoted osteoblast differentiation through targeting DKK1. & [89] \\
\hline $\operatorname{miR}-133 a-5 p$ & Runx2 & Osteoblasts & $\begin{array}{l}\text { miR-133a-5p inhibited the expression of osteoblast differentiation-associated markers by } \\
\text { targeting the 3' UTR of RUNX2. }\end{array}$ & {$[58]$} \\
\hline $\operatorname{miR}-467 \mathrm{~g}$ & $\begin{array}{l}\text { Ihh/Runx- } \\
\quad 2\end{array}$ & Osteoblasts & miR-467g inhibited new bone regeneration by targeting Ihh/Runx-2 signaling. & {$[59]$} \\
\hline $\operatorname{miR}-208 a-3 p$ & ACVR1 & Osteoblasts & $\begin{array}{c}\text { miR-208a-3p suppresses osteoblast differentiation and inhibits bone formation } \\
\text { by targeting ACVR1. }\end{array}$ & {$[90]$} \\
\hline
\end{tabular}

MSCs: mesenchymal stem cells; BMSCs: bone marrow mesenchymal stem cells.

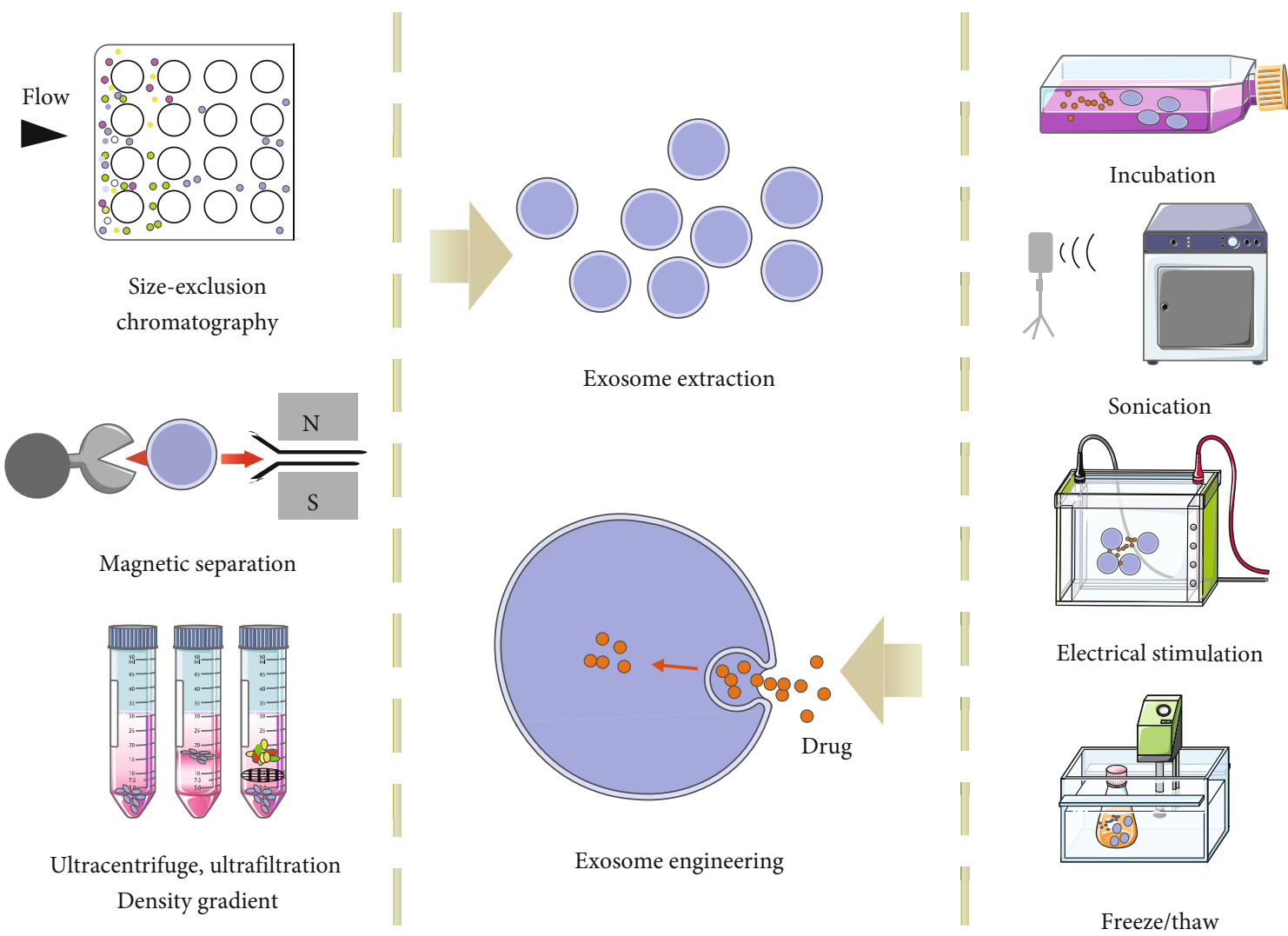

FIgURE 4: Methods of exosome extraction and engineering. 
TABLE 3: Comparison of methods about exosome extraction.

\begin{tabular}{|c|c|c|c|c|}
\hline Name & Method & Advantage & Disadvantage & Ref. \\
\hline Ultracentrifuge & $\begin{array}{l}\text { (1) Low speed to remove cells and apoptotic } \\
\text { debris } \\
\text { (2) High speed to eliminate larger vesicles } \\
\text { (3) Higher speed to precipitate exosomes }\end{array}$ & $\begin{array}{l}\text { (1) The gold standard for } \\
\text { exosome extraction } \\
\text { (2) Simple operation }\end{array}$ & $\begin{array}{l}\text { (1) A lot of materials need to be } \\
\text { prepared in the early stage } \\
\text { (2) The exosome yield is low } \\
\text { (3) Repeated centrifugation } \\
\text { causes damage to exosome } \\
\text { vesicles and reduces its quality } \\
\text { (4) Soluble proteins can form } \\
\text { clumps with exosomes and cause } \\
\text { pollution }\end{array}$ & {$[78]$} \\
\hline
\end{tabular}

$\begin{array}{ll}\begin{array}{l}\text { Concentration } \\ \text { gradient }\end{array} & \begin{array}{l}\text { In different liquid density intervals, each particle } \\ \text { will eventually stay at the same position as its own } \\ \text { centrifugation }\end{array} \\ \text { density }\end{array}$

gradien

centrifugation density
Compared with

ultracentrifugation, the recovery rate and purity are higher
Same as above

$[78$, 82]

(1) The adhesion of the filter membrane may lose exosomes (2) The pressure and shearing force during filtration may cause of the damage of exosomes

(1) Low efficiency

(2) Biological activity is easily affected by $\mathrm{pH}$ and salt concentration antimarker antibodies, exosomes can be adsorbed (3) Not affecting the and separated exosomal morphological integrity

(3) Not conducive to

downstream experiments

(1) Time-consuming

Exosomes are not affected (2) Not suitable for large sample by shear forces processing

(3) Special equipment required
[81] microspheres according to their diameter. Molecules with a small radius take longer to migrate through the pores of the column
Size-exclusion
chromatography
With columns filled with porous polymer microspheres, molecules pass through the

[100], extrusion, freeze/thaw [101], click chemistry [102, 103], and antibody binding [104] (Figure 4).

We concentrate on methods and applications of fusing exogenous RNA into exosomes. One mean is through electroporation of exosomes. Researchers electroplated siRNA into dendritic cell-derived exosomes. Up to 60\% GAPDH RNA and protein were knocked down in the mouse cortex, midbrain, and striatum by intravenous injection of electroplated exosomes [98]. Electroplating of siRNA against MAPK-1 into exosomes derived from peripheral blood monocytes reduced the expression of MAPK-1 in donor lymphocytes and monocytes [105]. In a conclusion, these results indicated that electroporation is wildly used in various kinds of exosomes and recipient cells. However, this method is inappropriate for all types of RNA cargo. For instance, researchers reported that miRNA cannot be electroplated into HEK 293-derived exosomes, indicating that some dimension or structure of RNA may be less suitable for this method [106].

Another strategy for fusing RNA into exosomes is overexpressing the cargo RNA in the exosome donor cells. The specificity of this method is poor. This kind of cargo RNA includes chemically modified 3' benzopyridine miRNA [99], mRNA [107, 108], and shRNA [109]. Researchers incubated exosomes carrying these RNAs with recipient cells. These mRNAs were translated into protein. Target genes were knocked down by shRNA and miRNA. This strategy is applicable to various RNA cargos and recipient cells.

5.3. Targeting Exosomes to Recipient Cells. The safe application of exosome therapy requires the assessment of potential exosomes targeting cell and subcellular regions. Although the pharmacokinetics of exosomes used by IV has not been elaborated, the application of purified exosomes in mice can cause exosomes to accumulate in the kidney, liver, and spleen $[98,106]$. This distribution is similar to most nanoparticle delivery vehicles, usually through bile excretion, kidney clearance, or macrophage clearance $[110,111]$. Strategies for exosomes to target specific recipient cells have been reported.

One strategy is to utilize proteins and peptides from the virus with the ability of targeted delivery. For example, researchers used EBV glycoprotein 350 modifying exosomes to target CD19+ B cells, but not other peripheral blood mononuclear cells (PBMCs) [112, 113]. Ligands of viruses can also enhance exosome-mediated transport to target cells in vivo. RVG-labeled exosomes transferred siRNA to the mouse brain, while unlabeled exosomes convey siRNA to the liver, spleen, and kidney [98]. Viral ligands can not only enhance the targeting ability of exosomes but also enhance the ability of exosomes to be integrated into the recipient cells. Exosomes labeled with VSV-G and OVA peptides are 
PBS

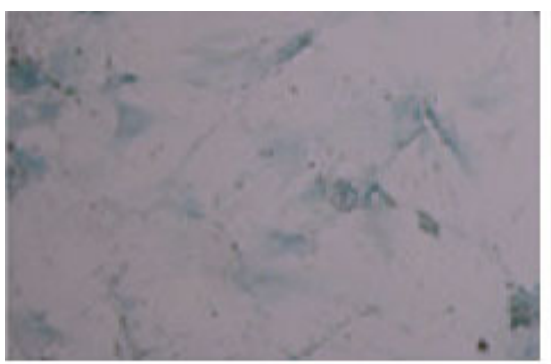

Chondrocyte exo/NC

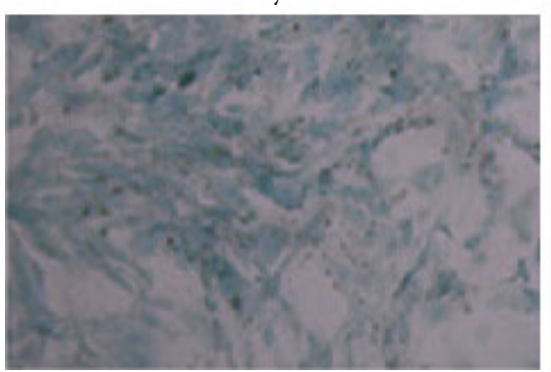

Chondrocyte exo

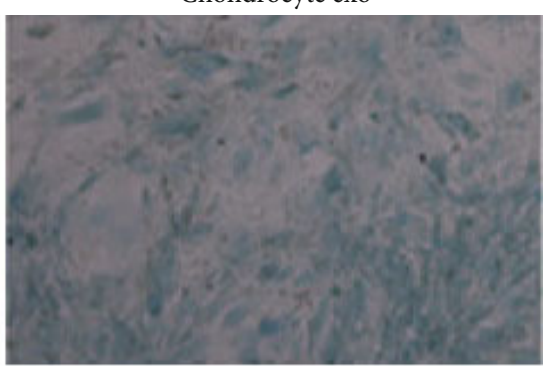

Chondrocyte exo/miR-inhibitor

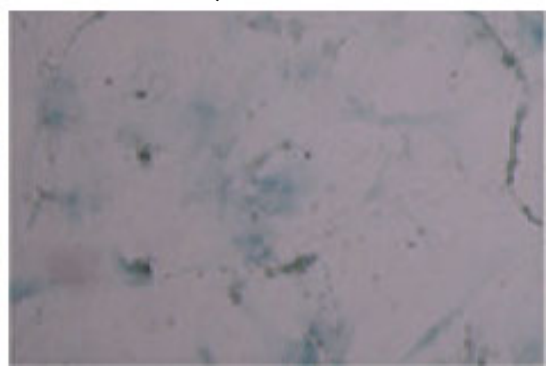

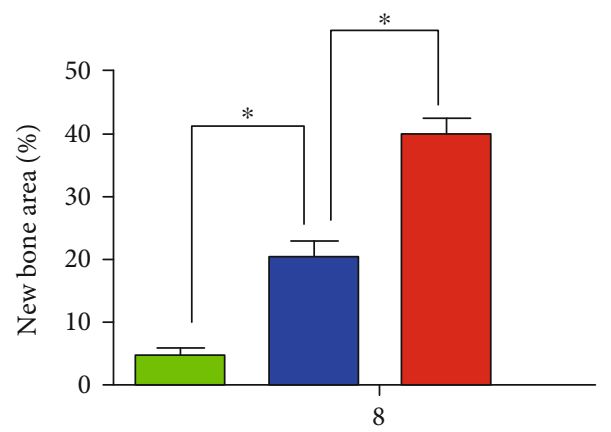

Implatation time (weeks)

$$
\begin{aligned}
& \text { Scaffold } \\
& \text { Scaffold }+100 \mu \text { g exos } \\
& \text { Scaffold }+200 \mu \text { g exos }
\end{aligned}
$$

(b)
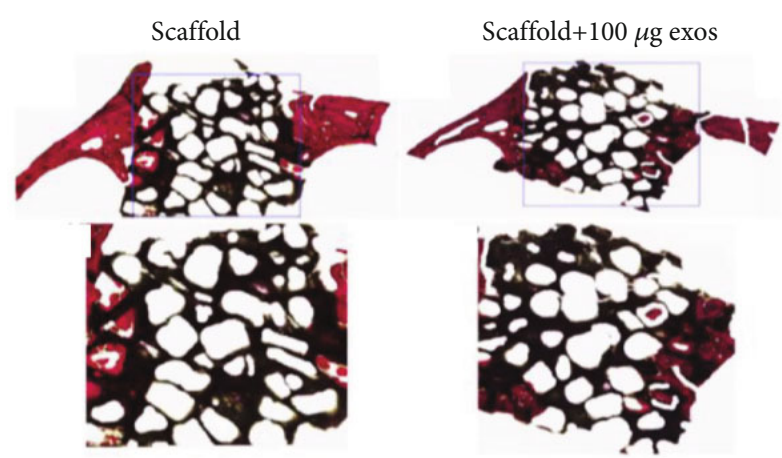

Scaffold $+200 \mu$ g exos

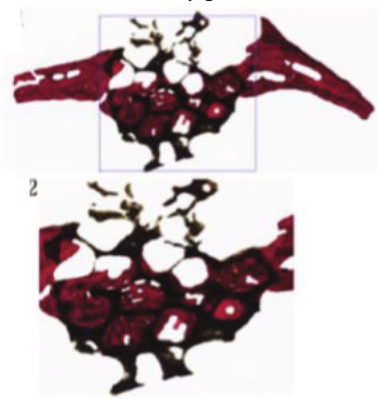

(c)

FIGURE 5: Effect of exosome on the differentiation of cells in vivo and vitro. In (a), the production of proteoglycan in BMSCs was induced by chondrocyte exosomes, but such effect was counteracted by chondrocyte exosomes with miR-8485 inhibitor. As is shown in (b) and (c), the results of Van Gieson staining of undecalcified specimens showed that bone regeneration was markedly increased in the scaffold $+200 \mu \mathrm{g}$ Exos group $(40.11 \pm 2.52 \%)$, and the percentage of new bone formation area was significantly greater than that in the scaffold group (4.52 $\pm 1.2 \%$ ) or the scaffold $+100 \mu$ g Exos group $(20.45 \pm 2.45 \%)(P<0.05)[33,52]$. (a) Copyright 2020 BBRC published by Elsevier Ltd. (b, c) Copyright 2016 Int J Biol Sci published by Ivyspring International Publisher.

absorbed by DC at a higher rate than exosomes labeled with OVA alone $[114,115]$. Although viruses can be used to improve the ability of exosome to target cells, the strategy is limited to the known interactions. The side effects of this strategy are still unknown.

\section{Exosome-Based Strategies for Restoration of Bone Defect}

Bone-derived exosome containing noncoding RNA is considered significant in regulating bone formation and absorption (Figure 5). Various key factors, regulating osteoclasts and osteoblasts (such as RUNX2, BMP, and sclerostin), are adjusted by specific bone-derived exosomes embodying noncoding RNA [116]. Studies showed that intravenously, exosomes tend to their original place [117].

However, the same noncoding exosomes may have opposite effect on the differentiation and proliferation of osteoclasts and osteoblasts. Therefore, during the process of bone remodeling, bone-derived exosomes may not have functions completely coherent with the parental cells. The abundance of noncoding RNA in recipient cells and exosomes does not 
match, indicating that in addition to noncoding RNA, other components of exosomes also have regulatory effects [118]. Researchers have utilized exosomes from other tissues to enhance tissue healing efficacy [119] and to reduce joint injury and osteoarthritis by restoring matrix homeostasis and decreasing inflammation [120]. Efforts were being made to test the effects of engineered exosomes on orthodontic tooth movement models in mouse [121].

\section{The Advantages of Exosomes as Noncoding RNA Delivery System}

7.1. Biocompatibility. The advantage of exosomes as drug carriers over existing artificial liposomes lies in their good biocompatibility. Currently, liposomes are the main delivery for siRNA and other RNAs. Liposomes can cause accumulated toxicity and immune response in the human body, without good expected effects. Kamerkar et al. used exosomes to deliver siRNA to prevent the production of KRAS mutant proteins. Research results showed that compared with liposomes, intravenous injection of siRNA-loaded exosomes can better inhibit the expression of KRAS protein, without immunogenicity in vivo [122]. Usman et al. used electroporation technology to introduce nucleotides into red blood cellderived exosomes. The results showed that the nucleotides loaded with exosomes have a significant inhibitory effect on breast cancer cells and there is no immunity in the body [123]. Compared with other RNA drug delivery vehicles (such as adenovirus, lentivirus, retrovirus, and liposome), exosomes are not immunogenic and cytotoxic, showing good biocompatibility.

7.2. Biological Stability. Exosomes derived from antigenpresenting cells can express membrane-bound complement regulators CD55 and CD59 to enhance the stability of circulation in the body [122]. Studies have shown that even if exposed to an inflammatory environment, exosomes still have a longer circulation time [124]. A large number of studies have proved that due to their small size $(\leq 100 \mathrm{~nm})$, nanoparticles can achieve targeted aggregation of tissues through enhanced penetration and retention effects [125]. In addition, the circulation time of polyethylene glycol-modified exosomes can reach more than 60 minutes in vivo [126]. Polyethylene glycol-modified exosomes can significantly improve the biological stability of exosomes in vivo by prolonging the clearance time, making the study of exosomes as drug carriers more promising.

7.3. Targeting. Multiple studies have confirmed the loyalty of exosomal cargo to parental cells. Exosomes derived from central nerve cells can pass through the blood-brain barrier and target specific neurons. Exosomes derived from hypoxic tumor cells tend to recruit into hypoxic tumor tissues [127, 128]. The results of biodistribution studies also showed that the accumulation of exosomes in tumor tissues depended on the type of embryonic cells. Therefore, when studying exosomes targeting specific tissues or cells, it is necessary to consider the targeting efficiency [129].

\section{Conclusions and Perspective}

Exosomes are increasingly being studied in the field of bone reconstruction. From the initial research on tumor diseases and related mechanisms to studies on drug delivery and engineering exosomes, there is still a lot of research space.

(1) How to select cells with strong ability to secrete exosomes? The scaffold used with MSCs provides an ideal environment for the osteogenic differentiation of MSCs [130][131]. However, there is no research on the inducing factors involved in this mechanism. Scaffold may enhance the paracrine function of MSCs, thereby secreting exosomes to induce the osteogenic differentiation. (2) The loading of exosomes on the scaffold to promote bone repair has been widely studied, but how to make the scaffold play a controlled or slow-release effect is another problem that needs to be solved. Maybe the solution is to control the pore size and degradation rate of the scaffold material. (3) Another direction is to improve their targeting ability by modifying the exosomal membrane molecules and preventing unwanted derivatives from entering the exosomes

Further research is needed to evaluate the biological efficacy of exosomes in treating bone defects in vivo and vitro. As therapeutic delivery vectors, exosomes have engineering potential, and they are easy to design and well tolerated in vivo. Overcoming each of these miseries will turn the surprise discovery of exosomes as a drug delivery system into a viable mature technology.

\section{Conflicts of Interest}

All the authors declare no conflict of interest.

\section{Authors' Contributions}

Keda Liu and Nanjue Cao contributed equally to this work.

\section{Acknowledgments}

This study was supported by the National Natural Science Foundation of China (No. 81970980); Liaoning Province, Colleges and Universities Basic Research Project (No. LFWK201717); Liaoning Provincial Key Research Plan Guidance Project (No. 2018225078); Liaoning Provincial Natural Science Foundation Guidance Project (No. 2019ZD-0749); Shenyang Major Scientific and Technological Innovation Research and Development Plan (No. 19-112-4027); Shenyang Young and Middle-aged Technological Innovation Talent Plan (No. RC200060); and the Second Batch of Medical Education Scientific Research Projects of the 13th Five-Year Plan of China Medical University (No. YDJK2018017).

\section{References}

[1] A. Šućur, V. Katavić, T. Kelava, Z. Jajić, N. Kovačić, and D. Grčević, "Induction of osteoclast progenitors in inflammatory conditions: key to bone destruction in arthritis," International Orthopaedics, vol. 38, no. 9, pp. 1893-1903, 2014. 
[2] A. Sieberath, E. Della Bella, A. M. Ferreira, P. Gentile, D. Eglin, and K. Dalgarno, "A comparison of osteoblast and osteoclast in vitro co-culture models and their translation for preclinical drug testing applications," International Journal of Molecular Sciences, vol. 21, no. 3, p. 912, 2020.

[3] T. Kowada, J. Kikuta, A. Kubo et al., "In vivo fluorescence imaging of bone-resorbing osteoclasts," Journal of the American Chemical Society, vol. 133, no. 44, pp. 17772-17776, 2011.

[4] W. Liu, L. H. Yang, X. C. Kong, L. K. An, and R. Wang, "Meta-analysis of osteoporosis: fracture risks, medication and treatment," Minerva Medica, vol. 106, no. 4, pp. 203214, 2015.

[5] S. C. Manolagas, "Steroids and osteoporosis: the quest for mechanisms," Journal of Clinical Investigation, vol. 123, no. 5, pp. 1919-1921, 2013.

[6] K. Zhang, Y. Fan, N. Dunne, and X. Li, "Effect of microporosity on scaffolds for bone tissue engineering," Regenerative Biomaterials, vol. 5, no. 2, pp. 115-124, 2018.

[7] K. Henriksen, M. A. Karsdal, and T. J. Martin, "Osteoclastderived coupling factors in bone remodeling," Calcified Tissue International, vol. 94, no. 1, pp. 88-97, 2014.

[8] T. Miyazaki, F. Tokimura, and S. Tanaka, "A review of denosumab for the treatment of osteoporosis," Patient Preference \& Adherence, vol. 8, pp. 463-471, 2014.

[9] G. Sánchez-Duffhues, C. Hiepen, P. Knaus, and P. ten Dijke, "Bone morphogenetic protein signaling in bone homeostasis," Bone, vol. 80, pp. 43-59, 2015.

[10] A. I. Alford, K. M. Kozloff, and K. D. Hankenson, "Extracellular matrix networks in bone remodeling," The International Journal of Biochemistry \& Cell Biology, vol. 65, pp. 20-31, 2015.

[11] L. Wang, S. Wu, G. X. Cao, Y. B. Fan, N. Dunne, and X. M. Li, "Biomechanical studies on biomaterial degradation and cocultured cells: mechanisms, potential applications, challenges and prospects," Journal of Materials Chemistry B, vol. 7, no. 47, pp. 7439-7459, 2019.

[12] S. E. Wang, "Extracellular vesicles and metastasis," Cold Spring Harbor Perspectives in Medicine, vol. 10, no. 7, article a037275, 2020.

[13] N. Huynh, L. VonMoss, D. Smith et al., "Characterization of regulatory extracellular vesicles from osteoclasts," Journal of Dental Research, vol. 95, no. 6, pp. 673-679, 2016.

[14] B. C. J. van der Eerden, "MicroRNAs in the skeleton: cellrestricted or potent intercellular communicators?," Archives of Biochemistry and Biophysics, vol. 561, pp. 46-55, 2014.

[15] H. X. Wang and O. Gires, "Tumor-derived extracellular vesicles in breast cancer: from bench to bedside," Cancer Letters, vol. 460, pp. 54-64, 2019.

[16] S. Lin, Z. Yu, D. Chen et al., "Progress in microfluidicsbased exosome separation and detection technologies for diagnostic applications," Small, vol. 16, no. 9, article 1903916, 2019.

[17] C. K. Das, B. C. Jena, I. Banerjee et al., "Exosome as a novel shuttle for delivery of therapeutics across biological barriers," Molecular Pharmaceutics, vol. 16, no. 1, pp. 24-40, 2019.

[18] A. J. Vázquez-Ríos, Á. Molina-Crespo, B. L. Bouzo, R. López-López, G. Moreno-Bueno, and M. de la Fuente, "Exosome-mimetic nanoplatforms for targeted cancer drug delivery," Journal of Nanobiotechnology, vol. 17, no. 1, p. $85,2019$.
[19] Ó. Rapado-González, A. Álvarez-Castro, R. López-López, J. Iglesias-Canle, M. M. Suárez-Cunqueiro, and L. MuineloRomay, "Circulating microRNAs as promising biomarkers in colorectal cancer," Cancers, vol. 11, no. 7, p. 898, 2019.

[20] Y. Zheng, L. Tang, L. Mabardi, S. Kumari, and D. J. Irvine, "Enhancing adoptive cell therapy of cancer through targeted delivery of small-molecule immunomodulators to internalizing or noninternalizing receptors," ACS Nano, vol. 11, no. 3, pp. 3089-3100, 2017.

[21] N. Xu, J. Li, Y. Gao et al., “Apoptotic cell-mimicking gold nanocages loaded with LXR agonist for attenuating the progression of murine systemic lupus erythematosus," Biomaterials, vol. 197, pp. 380-392, 2019.

[22] E. G. Trams, C. J. Lauter, J. Norman Salem, and U. Heine, "Exfoliation of membrane ecto-enzymes in the form of micro-vesicles," Biochimica et Biophysica Acta (BBA) - Biomembranes, vol. 645, no. 1, pp. 63-70, 1981.

[23] G. Raposo, H. W. Nijman, W. Stoorvogel et al., "B lymphocytes secrete antigen-presenting vesicles," The Journal of Experimental Medicine, vol. 183, no. 3, pp. 1161-1172, 1996.

[24] D. M. Pegtel, K. Cosmopoulos, D. A. Thorley-Lawson et al., "Functional delivery of viral miRNAs via exosomes," Proceedings of the National Academy of Sciences of the United States of America, vol. 107, no. 14, pp. 6328-6333, 2010.

[25] N. Kosaka, H. Iguchi, Y. Yoshioka, F. Takeshita, Y. Matsuki, and T. Ochiya, "Secretory mechanisms and intercellular transfer of microRNAs in living cells," The Journal of Biological Chemistry, vol. 285, no. 23, pp. 17442-17452, 2010.

[26] Y. Zhang, D. Liu, X. Chen et al., "Secreted monocytic miR150 enhances targeted endothelial cell migration," Molecular Cell, vol. 39, no. 1, pp. 133-144, 2010.

[27] T. L. Whiteside, "Tumor-derived exosomes and their role in cancer progression," Advances in Clinical Chemistry, vol. 74, pp. 103-141, 2016.

[28] L. Wang, C. Y. Wang, S. Wu, Y. B. Fan, and X. M. Li, "Influence of mechanical properties of biomaterials on degradability, cell behaviors and signaling pathways: current progress and challenges," Biomaterials Science, vol. 8, no. 10, pp. 2714-2733, 2020.

[29] A. Głuszko, M. J. Szczepański, N. Ludwig, S. M. Mirza, and W. Olejarz, "Exosomes in cancer: circulating immunerelated biomarkers," BioMed Research International, vol. 2019, Article ID 1628029, 9 pages, 2019.

[30] N. Gong, W. Zhu, R. Xu et al., "Keratinocytes-derived exosomal miRNA regulates osteoclast differentiation in middle ear cholesteatoma," Biochemical and Biophysical Research Communications, vol. 525, no. 2, pp. 341-347, 2020.

[31] L. Deng, Y. Wang, Y. Peng et al., "Osteoblast-derived microvesicles: A novel mechanism for communication between osteoblasts and osteoclasts," Bone, vol. 79, pp. 37-42, 2015.

[32] L. Lieben, "Direct contact between mature osteoblasts and osteoclasts," Nature Reviews Rheumatology, vol. 14, no. 4, p. 183, 2018.

[33] X. Qi, J. Zhang, H. Yuan et al., "Exosomes secreted by human-induced pluripotent stem cell-derived mesenchymal stem cells repair critical-sized bone defects through enhanced angiogenesis and osteogenesis in osteoporotic rats," International Journal of Biological Sciences, vol. 12, no. 7, pp. 836849, 2016.

[34] P. Kucharzewska, H. C. Christianson, J. E. Welch et al., "Exosomes reflect the hypoxic status of glioma cells and mediate 
hypoxia-dependent activation of vascular cells during tumor development," Proceedings of the National Academy of Sciences of the United States of America, vol. 110, no. 18, pp. 7312-7317, 2013.

[35] M. Ghorbanian, S. Babashah, and F. Ataei, "The effects of ovarian cancer cell-derived exosomes on vascular endothelial growth factor expression in endothelial cells," EXCLI Journal, vol. 18, pp. 899-907, 2019.

[36] J. Ratajczak, K. Miekus, M. Kucia et al., "Embryonic stem cellderived microvesicles reprogram hematopoietic progenitors: evidence for horizontal transfer of mRNA and protein delivery," Leukemia, vol. 20, no. 5, pp. 847-856, 2006.

[37] M. C. Deregibus, V. Cantaluppi, R. Calogero et al., "Endothelial progenitor cell derived microvesicles activate an angiogenic program in endothelial cells by a horizontal transfer of mRNA," Blood, vol. 110, no. 7, pp. 2440-2448, 2007.

[38] H. Valadi, K. Ekström, A. Bossios, M. Sjöstrand, J. J. Lee, and J. O. Lötvall, "Exosome-mediated transfer of mRNAs and microRNAs is a novel mechanism of genetic exchange between cells," Nature Cell Biology, vol. 9, no. 6, pp. 654659, 2007.

[39] F. Fatima and M. Nawaz, "Vesiculated long non-coding RNAs: offshore packages deciphering trans-regulation between cells, cancer progression and resistance to therapies," Non-Coding RNA, vol. 3, no. 1, p. 10, 2017.

[40] L. S. Holliday, A. D. Dean, R. H. Lin, J. E. Greenwald, and S. L. Gluck, "Low NO concentrations inhibit osteoclast formation in mouse marrow cultures by cGMP-dependent mechanism," The American Journal of Physiology, vol. 272, no. 3, pp. F283F291, 1997.

[41] X. Wang, B. Guo, Q. Li et al., "miR-214 targets _ATF4_to inhibit bone formation," Nature Medicine, vol. 19, no. 1, pp. 93-100, 2013.

[42] T. Wang, C. H. Sun, H. B. Zhong et al., "N-(3-Methoxybenzyl) -(9Z,12Z,15Z)-octadecatrienamide promotes bone formation via the canonical $\mathrm{Wnt} / \beta$-catenin signaling pathway," Phytotherapy Research, vol. 33, no. 4, pp. 10741083, 2019.

[43] D. Li, J. Liu, B. Guo et al., "Osteoclast-derived exosomal miR214-3p inhibits osteoblastic bone formation," Nature Communications, vol. 7, no. 1, article 10872, 2016.

[44] W. Sun, C. Zhao, Y. Li et al., "Osteoclast-derived microRNAcontaining exosomes selectively inhibit osteoblast activity," Cell Discovery, vol. 2, no. 1, article 16015, 2016.

[45] L. S. Holliday, K. P. McHugh, J. Zuo, J. I. Aguirre, J. K. Neubert, and W. J. Rody Jr., "Exosomes: novel regulators of bone remodelling and potential therapeutic agents for orthodontics," Orthodontics \& Craniofacial Research, vol. 20, Supplement 1, pp. 95-99, 2017.

[46] M. Fu, G. Huang, Z. Zhang et al., "Expression profile of long noncoding RNAs in cartilage from knee osteoarthritis patients," Osteoarthritis and Cartilage, vol. 23, no. 3, pp. 423-432, 2015.

[47] Z. Zhang, Y. Kang, Z. Zhang et al., "Expression of microRNAs during chondrogenesis of human adipose-derived stem cells," Osteoarthritis and Cartilage, vol. 20, no. 12, pp. 1638-1646, 2012.

[48] T. Xu, Y. Luo, J. Wang et al., "Exosomal miRNA-128-3p from mesenchymal stem cells of aged rats regulates osteogenesis and bone fracture healing by targeting Smad5," Journal of Nanobiotechnology, vol. 18, no. 1, p. 47, 2020.
[49] R. Wang, W. Jiang, L. Zhang et al., "Intra-articular delivery of extracellular vesicles secreted by chondrogenic progenitor cells from MRL/MpJ superhealer mice enhances articular cartilage repair in a mouse injury model," Stem Cell Research \& Therapy, vol. 11, no. 1, p. 93, 2020.

[50] G. W. Lee, M. Thangavelu, M. J. Choi et al., "Exosome mediated transfer of miRNA-140 promotes enhanced chondrogenic differentiation of bone marrow stem cells for enhanced cartilage repair and regeneration," Journal of Cellular Biochemistry, vol. 121, no. 7, pp. 3642-3652, 2020.

[51] B. C. Yang, M. J. Kuang, J. Y. Kang, J. Zhao, J. X. Ma, and X. L. $\mathrm{Ma}$, "Human umbilical cord mesenchymal stem cell-derived exosomes act via the miR-1263/Mob1/Hippo signaling pathway to prevent apoptosis in disuse osteoporosis," Biochemical and Biophysical Research Communications, vol. 524, no. 4, pp. 883-889, 2020.

[52] Z. Li, Y. Wang, S. Xiang et al., "Chondrocytes-derived exosomal miR-8485 regulated the Wnt/ $\beta$-catenin pathways to promote chondrogenic differentiation of BMSCs," Biochemical and Biophysical Research Communications, vol. 523, no. 2, pp. 506-513, 2020.

[53] J. Zheng, L. Zhu, I. Iok in, Y. Chen, N. Jia, and W. Zhu, "Bone marrow-derived mesenchymal stem cells-secreted exosomal microRNA-192-5p delays inflammatory response in rheumatoid arthritis," International Immunopharmacology, vol. 78, p. 105985, 2020.

[54] Q. Leng, L. Chen, and Y. Lv, "RNA-based scaffolds for bone regeneration: application and mechanisms of mRNA, miRNA and siRNA," Theranostics, vol. 10, no. 7, pp. 31903205, 2020.

[55] J. Zheng, X. Zhang, Y. Zhang, and F. Yuan, "Osteoblast differentiation of bone marrow stromal cells by femtosecond laser bone ablation," Biomedical Optics Express, vol. 11, no. 2, pp. 885-894, 2020.

[56] Y. Zhang, Y. Gao, L. Cai et al., "MicroRNA-221 is involved in the regulation of osteoporosis through regulates RUNX2 protein expression and osteoblast differentiation," American Journal of Translational Research, vol. 9, no. 1, pp. 126-135, 2017.

[57] X. Zheng, J. Dai, H. Zhang, and Z. Ge, "MicroRNA-221 promotes cell proliferation, migration, and differentiation by regulation of ZFPM2 in osteoblasts," Brazilian Journal of Medical and Biological Research, vol. 51, no. 12, article e7574, 2018.

[58] W. Zhang, Y. Wu, Y. Shiozaki et al., "miRNA-133a-5p inhibits the expression of osteoblast differentiationassociated markers by targeting the 3' UTR of RUNX2," DNA and Cell Biology, vol. 37, no. 3, pp. 199-209, 2018.

[59] J. Kureel, A. A. John, M. Dixit, and D. Singh, "MicroRNA$467 \mathrm{~g}$ inhibits new bone regeneration by targeting Ihh/Runx2 signaling," The International Journal of Biochemistry \& Cell Biology, vol. 85, pp. 35-43, 2017.

[60] M. Han, L. Chen, and Y. Wang, " $m i R-218$ overexpression suppresses tumorigenesis of papillary thyroid cancer via inactivation of PTEN /PI3K/AKT pathway by targeting Runx2," OncoTargets and therapy, vol. 11, pp. 6305-6316, 2018.

[61] B. Qu, X. Xia, M. Yan et al., "miR-218 is involved in the negative regulation of osteoclastogenesis and bone resorption by partial suppression of p38MAPK-c-Fos-NFATc1 signaling: potential role for osteopenic diseases," Experimental Cell Research, vol. 338, no. 1, pp. 89-96, 2015.

[62] A. Asgharzadeh, S. Alizadeh, M. R. Keramati et al., "Upregulation of miR-210 promotes differentiation of mesenchymal 
stem cells (MSCs) into osteoblasts," Bosnian Journal of Basic Medical Sciences, vol. 18, no. 4, pp. 328-335, 2018.

[63] Y. Jin, F. Hong, Q. Bao et al., "MicroRNA-145 suppresses osteogenic differentiation of human jaw bone marrow mesenchymal stem cells partially via targeting semaphorin 3A," Connective Tissue Research, pp. 1-9, 2019.

[64] S. Fang, Y. Deng, P. Gu, and X. Fan, "MicroRNAs regulate bone development and regeneration," International Journal of Molecular Sciences, vol. 16, no. 4, pp. 8227-8253, 2015.

[65] J. Tian, Y. J. Rui, Y. J. Xu, and S. A. Zhang, "MiR-143-3p regulates early cartilage differentiation of BMSCs and promotes cartilage damage repair through targeting BMPR2," European Review for Medical and Pharmacological Sciences, vol. 22, no. 24, pp. 8814-8821, 2018.

[66] J.-y. Wang, Y. Yang, Y. Ma et al., "Potential regulatory role of lncRNA-miRNA-mRNA axis in osteosarcoma," Biomedicine \& Pharmacotherapy, vol. 121, p. 109627, 2020.

[67] L. Zhu and P. C. Xu, "Downregulated LncRNA-ANCR promotes osteoblast differentiation by targeting EZH2 and regulating Runx2 expression," Biochemical and Biophysical Research Communications, vol. 432, no. 4, pp. 612-617, 2013.

[68] C. Yu, L. Li, F. Xie et al., "LncRNA TUG1 sponges miR-204$5 p$ to promote osteoblast differentiation through upregulating Runx2 in aortic valve calcification," Cardiovascular Research, vol. 114, no. 1, pp. 168-179, 2018.

[69] L. Yu, H. Qu, Y. Yu, W. Li, Y. Zhao, and G. Qiu, "LncRNAPCAT1 targeting miR-145-5p promotes TLR4-associated osteogenic differentiation of adipose-derived stem cells," Journal of Cellular and Molecular Medicine, vol. 22, no. 12, pp. 6134-6147, 2018.

[70] R. Wu, J. Ruan, Y. Sun et al., "Long non-coding RNA HIF1AAS2 facilitates adipose-derived stem cells (ASCs) osteogenic differentiation through miR-665/IL6 axis via PI3K/Akt signaling pathway," Stem Cell Research \& Therapy, vol. 9, no. 1, p. 348, 2018.

[71] L. Deng, H. Hong, X. Zhang et al., "Down-regulated lncRNA MEG3 promotes osteogenic differentiation of human dental follicle stem cells by epigenetically regulating Wnt pathway," Biochemical and Biophysical Research Communications, vol. 503, no. 3, pp. 2061-2067, 2018.

[72] X. Yang, J. Yang, P. Lei, and T. Wen, "LncRNA MALAT1 shuttled by bone marrow-derived mesenchymal stem cellssecreted exosomes alleviates osteoporosis through mediating microRNA-34c/SATB2 axis," Aging, vol. 11, no. 20, pp. 8777-8791, 2019.

[73] B. Li, H. Xu, H. Han et al., "Exosome-mediated transfer of lncRUNX2-AS1 from multiple myeloma cells to MSCs contributes to osteogenesis," Oncogene, vol. 37, no. 41, pp. 5508-5519, 2018.

[74] X. Huang, X. Cen, B. Zhang et al., "Prospect of circular RNA in osteogenesis: a novel orchestrator of signaling pathways," Journal of Cellular Physiology, vol. 234, no. 12, pp. 2145021459, 2019.

[75] H. Wang, C. Feng, Y. Jin, W. Tan, and F. Wei, "Identification and characterization of circular RNAs involved in mechanical force-induced periodontal ligament stem cells," Journal of Cellular Physiology, vol. 234, no. 7, pp. 10166-10177, 2019.

[76] M. Zhang, L. Jia, and Y. Zheng, "circRNA expression profiles in human bone marrow stem cells undergoing osteoblast differentiation," Stem Cell Reviews and Reports, vol. 15, no. 1, pp. 126-138, 2019.
[77] Y. Mizuno, Y. Tokuzawa, Y. Ninomiya et al., "miR-210 promotes osteoblastic differentiation through inhibition of AcvR1b," FEBS Letters, vol. 583, no. 13, pp. 2263-2268, 2009.

[78] J. Zhang, Q. Tu, L. F. Bonewald et al., "Effects of miR-335-5p in modulating osteogenic differentiation by specifically downregulating Wnt antagonist DKK1," Journal of Bone and Mineral Research, vol. 26, no. 8, pp. 1953-1963, 2011.

[79] W. Peng, S. Zhu, J. Chen, J. Wang, Q. Rong, and S. Chen, "Hsa_circRNA_33287 promotes the osteogenic differentiation of maxillary sinus membrane stem cells via miR-2143p/Runx3," Biomedicine \& Pharmacotherapy, vol. 109, pp. 1709-1717, 2019.

[80] D. Y. Qian, G. B. Yan, B. Bai et al., "Differential circRNA expression profiles during the BMP2-induced osteogenic differentiation of MC3T3-E1 cells," Biomedicine \& Pharmacotherap, vol. 90, pp. 492-499, 2017.

[81] Q. Xing, P. de Vos, M. M. Faas, Q. Ye, and Y. Ren, "LPS promotes pre-osteoclast activity by up-regulating CXCR4 via TLR-4," Journal of Dental Research, vol. 90, no. 2, pp. 157162, 2011.

[82] A. Huang, H. Zheng, Z. Wu, M. Chen, and Y. Huang, "Circular RNA-protein interactions: functions, mechanisms, and identification," Theranostics, vol. 10, no. 8, pp. 3503-3517, 2020.

[83] Y. Zheng, X. Li, Y. Huang, L. Jia, and W. Li, “The circular RNA landscape of periodontal ligament stem cells during osteogenesis," Journal of Periodontology, vol. 88, no. 9, pp. 906-914, 2017.

[84] S. Chen, Y. Tang, Y. Liu et al., "Exosomes derived from miR375-overexpressing human adipose mesenchymal stem cells promote bone regeneration," Cell Proliferation, vol. 52, no. 5, article e12669, 2019.

[85] Z. Jin, J. Ren, and S. Qi, "Human bone mesenchymal stem cells-derived exosomes overexpressing microRNA-26a-5p alleviate osteoarthritis via down-regulation of PTGS2," International Immunopharmacology, vol. 78, article 105946, 2020.

[86] H. Song, X. Li, Z. Zhao et al., "Reversal of osteoporotic activity by endothelial cell-secreted bone targeting and biocompatible exosomes," Nano Letters, vol. 19, no. 5, pp. 30403048, 2019.

[87] S. Raimondo, O. Urzì, A. Conigliaro et al., "Extracellular vesicle microRNAs contribute to the osteogenic inhibition of mesenchymal stem cells in multiple myeloma," Cancers, vol. 12, no. 2, p. 449, 2020.

[88] X. Zhang, Y. Zhu, C. Zhang et al., "miR-542-3p prevents ovariectomy-induced osteoporosis in rats via targeting SFRP1," Journal of Cellular Physiology, vol. 233, no. 9, pp. 6798-6806, 2018.

[89] X. Tang, J. Lin, G. Wang, and J. Lu, "MicroRNA-433-3p promotes osteoblast differentiation through targeting DKK1 expression," PLoS One, vol. 12, no. 6, article e0179860, 2017.

[90] Y. Arfat, M. A. R. Basra, M. Shahzad, K. Majeed, N. Mahmood, and H. Munir, "miR-208a-3p Suppresses Osteoblast Differentiation and Inhibits Bone Formation by Targeting ACVR1," Molecular Therapy - Nucleic Acids, vol. 11, pp. 323-336, 2018.

[91] D. W. Greening, R. Xu, H. Ji, B. J. Tauro, and R. J. Simpson, "A protocol for exosome isolation and characterization: evaluation of ultracentrifugation, density-gradient separation, and immunoaffinity capture methods," Methods in Molecular Biology, vol. 1295, pp. 179-209, 2015. 
[92] M. P. Oksvold, A. Neurauter, and K. W. Pedersen, "Magnetic bead-based isolation of exosomes," Methods in Molecular Biology, vol. 1218, pp. 465-481, 2015.

[93] R. J. Lobb, M. Becker, S. Wen Wen et al., "Optimized exosome isolation protocol for cell culture supernatant and human plasma," Journal of Extracellular Vesicles, vol. 4, no. 1, p. 27031, 2015.

[94] Y. Q. Koh, F. B. Almughlliq, K. Vaswani, H. N. Peiris, and M. D. Mitchell, "Exosome enrichment by ultracentrifugation and size exclusion chromatography," Frontiers in Bioscience, vol. 23, pp. 865-874, 2018.

[95] B. Shen, N. Wu, J.-M. Yang, and S. J. Gould, "Protein targeting to exosomes/microvesicles by plasma membrane anchors," Journal of Biological Chemistry, vol. 286, no. 16, pp. 14383-14395, 2011.

[96] D. Sun, X. Zhuang, X. Xiang et al., “A novel nanoparticle drug delivery system: the anti-inflammatory activity of curcumin is enhanced when encapsulated in exosomes," Molecular Therapy, vol. 18, no. 9, pp. 1606-1614, 2010.

[97] R. Chen, H. Huang, H. Liu et al., "Friend or foe? Evidence indicates endogenous exosomes can deliver functional gRNA and Cas9 protein," Small, vol. 15, no. 38, article e1902686, 2019.

[98] L. Alvarez-Erviti, Y. Seow, H. Yin, C. Betts, S. Lakhal, and M. J. Wood, "Delivery of siRNA to the mouse brain by systemic injection of targeted exosomes," Nature Biotechnology, vol. 29, no. 4, pp. 341-345, 2011.

[99] Y. Akao, A. Iio, T. Itoh et al., "Microvesicle-mediated RNA molecule delivery system using monocytes/macrophages," Molecular Therapy, vol. 19, no. 2, pp. 395-399, 2011.

[100] M. J. Haney, N. L. Klyachko, Y. Zhao et al., "Exosomes as drug delivery vehicles for Parkinson's disease therapy," Journal of Controlled Release, vol. 207, pp. 18-30, 2015.

[101] G. Fuhrmann, A. Serio, M. Mazo, R. Nair, and M. M. Stevens, "Active loading into extracellular vesicles significantly improves the cellular uptake and photodynamic effect of porphyrins," Journal of Controlled Release, vol. 205, pp. 35-44, 2015.

[102] T. Smyth, K. Petrova, N. M. Payton et al., "Surface functionalization of exosomes using click chemistry," Bioconjugate Chemistry, vol. 25, no. 10, pp. 1777-1784, 2014.

[103] X. M. Li, J. R. Wei, K. E. Aifantis et al., "Current investigations into magnetic nanoparticles for biomedical application," Journal of Biomedical Materials Research Part A, vol. 104, no. 5, pp. 1285-1296, 2016.

[104] J. N. Higginbotham, Q. Zhang, D. K. Jeppesen et al., "Identification and characterization of EGF receptor in individual exosomes by fluorescence-activated vesicle sorting," Journal of Extracellular Vesicles, vol. 5, no. 1, article 29254, 2016.

[105] J. Wahlgren, T. D. L. Karlson, M. Brisslert et al., "Plasma exosomes can deliver exogenous short interfering RNA to monocytes and lymphocytes," Nucleic Acids Research, vol. 40, no. 17, article e130, 2012.

[106] S. Ohno, M. Takanashi, K. Sudo et al., "Systemically injected exosomes targeted to EGFR deliver antitumor microRNA to breast cancer cells," Molecular Therapy, vol. 21, no. 1, pp. 185-191, 2013.

[107] E. Hergenreider, S. Heydt, K. Tréguer et al., "Atheroprotective communication between endothelial cells and smooth muscle cells through miRNAs," Nature Cell Biology, vol. 14, no. 3, pp. 249-256, 2012.
[108] A. Mizrak, M. F. Bolukbasi, G. B. Ozdener et al., "Genetically engineered microvesicles carrying suicide mRNA/protein inhibit schwannoma tumor growth," Molecular Therapy, vol. 21, no. 1, pp. 101-108, 2013.

[109] O. Rechavi, Y. Erlich, H. Amram et al., "Cell contactdependent acquisition of cellular and viral nonautonomously encoded small RNAs," Genes \& Development, vol. 23, no. 16, pp. 1971-1979, 2009.

[110] H. Iguchi, N. Kosaka, and T. Ochiya, "Secretory microRNAs as a versatile communication tool," Communicative \& Integrative Biology, vol. 3, no. 5, pp. 478-481, 2014.

[111] Y. W. Yi, J. H. Lee, S. Y. Kim et al., "Advances in analysis of biodistribution of exosomes by molecular imaging," International Journal of Molecular Sciences, vol. 21, no. 2, p. 665, 2020.

[112] R. Ruiss, S. Jochum, R. Mocikat, W. Hammerschmidt, and R. Zeidler, "EBV-gp350 confers B-cell tropism to tailored exosomes and is a neo-antigen in normal and malignant $\mathrm{B}$ cells-a new option for the treatment of B-CLL," PLoS One, vol. 6, no. 10, article e25294, 2011.

[113] A. Farina, G. Peruzzi, V. Lacconi et al., "Epstein-Barr virus lytic infection promotes activation of Toll-like receptor 8 innate immune response in systemic sclerosis monocytes," Arthritis Research \& Therapy, vol. 19, no. 1, p. 39, 2017.

[114] V. V. Temchura, M. Tenbusch, G. Nchinda et al., "Enhancement of immunostimulatory properties of exosomal vaccines by incorporation of fusion-competent $\mathrm{G}$ protein of vesicular stomatitis virus," Vaccine, vol. 26, no. 29-30, pp. 3662-3672, 2008.

[115] Y. Yang, Y. Hong, G. H. Nam, J. H. Chung, E. Koh, and I. S. Kim, "Virus-mimetic fusogenic exosomes for direct delivery of integral membrane proteins to target cell membranes," Advanced Materials, vol. 29, no. 13, article 1605604, 2017.

[116] Y. Qin, R. Sun, C. Wu, L. Wang, and C. Zhang, "Exosome: a novel approach to stimulate bone regeneration through regulation of osteogenesis and angiogenesis," International Journal of Molecular Sciences, vol. 17, no. 5, p. 712, 2016.

[117] O. P. B. Wiklander, J. Z. Nordin, A. O'Loughlin et al., "Extracellular vesicle in vivo biodistribution is determined by cell source, route of administration and targeting," Journal of Extracellular Vesicles, vol. 4, no. 1, article 26316, 2015.

[118] Y. Cui, J. Luan, H. Li, X. Zhou, and J. Han, "Exosomes derived from mineralizing osteoblasts promote ST2 cell osteogenic differentiation by alteration of microRNA expression," FEBS Letters, vol. 590, no. 1, pp. 185-192, 2016.

[119] Y. Nakamura, S. Miyaki, H. Ishitobi et al., "Mesenchymalstem-cell-derived exosomes accelerate skeletal muscle regeneration," FEBS Letters, vol. 589, no. 11, pp. 1257-1265, 2015.

[120] J. Li, E. Hosseini-Beheshti, G. Grau, H. Zreiqat, and C. Little, "Stem cell-derived extracellular vesicles for treating joint injury and osteoarthritis," Nanomaterials, vol. 9, no. 2, p. 261, 2019.

[121] E. J. Toro, J. Zuo, A. Gutierrez et al., "Bis-enoxacin inhibits bone resorption and orthodontic tooth movement," Journal of Dental Research, vol. 92, no. 10, pp. 925-931, 2013.

[122] S. Kamerkar, V. S. LeBleu, H. Sugimoto et al., "Exosomes facilitate therapeutic targeting of oncogenic KRAS in pancreatic cancer," Nature, vol. 546, no. 7659, pp. 498-503, 2017.

[123] W. M. Usman, T. C. Pham, Y. Y. Kwok et al., "Efficient RNA drug delivery using red blood cell extracellular vesicles," Nature Communications, vol. 9, no. 1, p. 2359, 2018. 
[124] J. P. Armstrong, M. N. Holme, and M. M. Stevens, "Re-engineering extracellular vesicles as smart nanoscale therapeutics," ACS Nano, vol. 11, no. 1, pp. 69-83, 2017.

[125] Y. Yang, X. Tai, K. Shi et al., “A new concept of enhancing immuno-chemotherapeutic effects against B16F10 tumor via systemic administration by taking advantages of the limitation of EPR effect," Theranostics, vol. 6, no. 12, pp. 2141-2160, 2016.

[126] S. A. A. Kooijmans, L. A. L. Fliervoet, R. van der Meel et al., "PEGylated and targeted extracellular vesicles display enhanced cell specificity and circulation time," Journal of Controlled Release, vol. 224, pp. 77-85, 2016.

[127] M. Shi, L. Sheng, T. Stewart, C. P. Zabetian, and J. Zhang, "New windows into the brain: central nervous systemderived extracellular vesicles in blood," Progress in Neurobiology, vol. 175, pp. 96-106, 2019.

[128] K. O. Jung, H. Jo, J. H. Yu, S. S. Gambhir, and G. Pratx, "Development and MPI tracking of novel hypoxia-targeted theranostic exosomes," Biomaterials, vol. 177, pp. 139-148, 2018.

[129] M. Mendt, S. Kamerkar, H. Sugimoto et al., "Generation and testing of clinical-grade exosomes for pancreatic cancer," JCI Insight, vol. 3, no. 8, 2018.

[130] M. Maqsood, M. Kang, X. Wu, J. Chen, L. Teng, and L. Qiu, "Adult mesenchymal stem cells and their exosomes: sources, characteristics, and application in regenerative medicine," Life Sciences, vol. 256, article 118002, 2020.

[131] K. Vaswani, Y. Q. Koh, F. B. Almughlliq, H. N. Peiris, and M. D. Mitchell, "A method for the isolation and enrichment of purified bovine milk exosomes," Reproductive Biology, vol. 17, no. 4, pp. 341-348, 2017. 